\title{
MANAJEMEN PENERIMAAN PESERTA DIDIK BARU SISTEM ZONASI TINGKAT SEKOLAH MENENGAH ATAS DI SEKAYU TAHUN PELAJARAN 2021/2022
}

\author{
Nurviana \\ Prodi Magister MPI, UIN Raden Fatah, Palembang \\ nurviana8686@gmail.com \\ Akmal Hawi \\ Prodi Magister MPI, UIN Raden Fatah, Palembang \\ akmalhawi123@gmail.com \\ Maryamah \\ Prodi Magister MPI, UIN Raden Fatah, Palembang \\ maryamah_uin@radenfatah.ac.id
}

DOI: 10.35719/jieman.v3i1.68

\begin{abstract}
Abstrak
Sekolah negeri berlabel unggul atau biasa disebut sekolah favorit hampir di setiap daerah menjadi masalah karena adanya ketimpangan status sekolah dengan sekolah lain yang berstatus tidak unggul, tidak favorit. Akibatnya, jumlah pelajar menumpuk di sekolah tersebut. Hal ini menyebabkan pentingnya manajemen didalam mempromosikan masingmasing lembaga utamanya lembaga yang tidak favorit. Penelitian ini bertujuan mendeskripsikan manajemen PPDB online di Sekayu yang meliputi: (1) perencanaan, (2) pengorganisasian, (3) pelaksanaan, (4) pengawasan. Penelitian bersifat deskriptif kualitatif dengan menggunakan metode pengumpulan data melalui wawancara, observasi, dan dokumentasi. Informan terdiri dari kepala sekolah/yang mewakili/ketua panitia PPDB. Hasil yang diperoleh dalam penelitian ini bahwa manajemen PPDB di Sekayu: 1) perencanaan kegiatan dilakukan sesuai
\end{abstract}


juknis dari pemerintah, 2) pengorganisasian dilakukan pasca pembentukan panitia yang terdiri dari pendidik dan tenaga kependidikan yang mengusai ICT, 3) pelaksanaan dilakukan secara online maupun secara offline, 4) pengawasan PPDB dilakukan oleh Dinas Pendidikan Provinsi Sumatera Selatan. Kesimpulan dari penelitian ini bahwa manajemen PPDB dilaksanakan sesuai dengan petunjuk teknis (juknis) dari pemerintah. Pendaftaran dilakukan secara online dan offline serta memberikan pelayanan yang prima kepada masyarakat dengan tetap mematuhi protokol kesehatan.

Kata Kunci: manajemen PPDB, sistem zonasi, Sekolah Menengah Atas

\section{Abstract}

State schools labeled as superior or commonly called favorite schools in almost every area are a problem because of the inequality in school status with other schools with no superior status, not favorites. So the number of students accumulate in the school. This causes the importance of management in promoting each institution, especially those that are not favorites. This study aims to describe the management of online new student admission in Sekayu which includes: (1) planning, (2) organizing, (3) implementing, (4) supervising. The research is descriptive qualitative using data collection methods through interviews, observations, and documentation. Informants consist of the principal/representative/head of the PPDB committee. The results obtained in this study that PPDB in Sekayu: 1) planning activities are carried out according to technical guidelines from the government, 2) organizing is carried out after the formation of a committee consisting of educators and education staff who master ICT, 3) implementation is carried out online and offline, 4) PPDB supervision is carried out by the South Sumatra Provincial Education Office. The conclusion of this study is that the management of PPDB is carried out in accordance with the technical guidelines (juknis) from the government. Registration is done online and offline and provides excellent service to the community while still complying with health protocols.

Keywords: management of new student admission, zoning system, senior high school 


\section{Pendahuluan}

UU Nomor 20 Tahun 2003 tentang Sisdiknas dalam Pasal 5 ayat 1 menyebutkan bahwa setiap warga negara mempunyai hak yang sama untuk memperoleh pendidikan yang bermutu. Akan tetapi persoalannya adalah Polemik yang terjadi pada pelaksanaan PPDB tahun sebelumnya yaitu pada jalur zonasi yang persentasenya cukup tinggi. Dikutip dalam lpmpbali.kemdikbud.go.id tanggal 16 Juni 2021, Polemik yang terjadi pada pelaksanaan PPDB tahun sebelumnya yaitu pada jalur zonasi yang persentasenya cukup tinggi ditanggapi Menteri Pendidikan dan Kebudayaan (Mendikbud) Nadiem Makarim dengan mengeluarkan kebijakan baru dimana jalur zonasi persentasenya diturunkan.

Menanggapi hal tersebut Kementerian Pendidikan dan Kebudayaan menetapkan Permendikbud Nomor 17 Tahun 2017 tentang Penerimaan Peserta Didik Baru pada Taman Kanak Kanak, Sekolah Dasar, Sekolah Menengah Pertama, Sekolah Menengah Atas, Sekolah Menengah Kejuruan atau bentuk Lain Yang Sederajat. Peraturan PPDB Zonasi tersebut juga telah diperbaharui Permendikbud Nomor 44 Tahun 2019. Sistem zonasi di Kota Sekayu sudah dijalankan dan mengacu pada Peraturan Gubernur (Pergub) tentang Penerimaan Peserta Didik Baru pada Sekolah Menengah Atas dan Sekolah Menengah Kejuruan di Provinsi Sumatera Selatan. ${ }^{1}$ Penelitian ini dilatarbelakangi oleh adanya kesulitan calon peserta didik baru untuk mendaftar sekolah di beberapa SMA yang terdapat di kota Sekayu. Salah satu sekolah yang sudah menerapkan PPDB online adalah SMA Negeri 2 Sekayu. Keunggulan SMA Negeri 2 Sekayu diantaranya adanya minat yang tinggi dari calon peserta didik, sarana dan prasarana lengkap dan memadai, tim IT yang proesional, letak sekolah strategis sehingga mudah dijangkau oleh transportasi umum.

Permasalahan pemerataan kualitas pendidikan yang masih terjadi di Indonesia meliputi kurangnya sarana dan prasarana penunjang pendidikan. Sebagai gambaran, antara lain data penelitian yang ditulis oleh Mona Novita, yaitu berdasarkan data

${ }^{1}$ Peraturan Gubernur Nomor. 8, BD.2020/No. 9 tentang Penerimaan Peserta Didik Baru pada Sekolah Menengah Atas dan Sekolah Menengah Kejuruan di Provinsi Sumatera Selatan. 
Balitbang Depdiknas tahun 2016, terdapat 88,8\% sekolah di Indonesia mulai dari SD sampai dengan tingkat SMA/SMK yang belum mencapai standar mutu pelayanan minimal. Pada pendidikan dasar hingga kini layanan pendidikan seperti guru, bangunan sekolah, fasilitas perpustakaan dan laboratorium, bukubuku pelajaran dan pengayaan serta buku-buku referensi masih minim. Pada jenjang SD terdapat 3,29\% dari 146.904 yang masuk kategori sekolah standar nasional, 51,71\% kategori sekolah yang memenuhi standar minimal dan 44,84\% kategori sekolah dibawah standar pendidikan minimal. Pada jenjang SMP 28,41\% dari 34.185 artinya $44,45 \%$ berstandar minimal dan 26 persen tidak memenuhi standar pelayanan minimal. ${ }^{2}$

Menurut Data Balitbang Depdiknas tahun 2003 diakses di laman Litbang.kemdikbud.go.id. oleh Mona Novita, untuk satuan SD, dari total keseluruhan berjumlah 146.052 lembaga pendidikan. Lembaga pendidikan tersebut dapat menampung sebanyak 25.918.898 orang siswa. Dari jumlah tersebut, 42,12\% ruang kelas dalam kondisi baik, 34,62\% ruang kelas rusak ringan dan $23,26 \%$ ruang kelas rusak berat (jumlah keseluruhan dari ruangan kelas adalah 865.258 ruang). Keadaan ini juga terjadi di SMP, MTs, SMA dan MA. Hal tersebut membuktikan bahwa pendidikan di Indonesia tidak terpenuhi sarana prasarana pendidikannya. Permasalahan tidak terpenuhi sarana prasarana pendidikan, menyebabkan peserta didik yang merasa memiliki potensi diri lebih tidak mau bersekolah di sekolah zona tempat tinggalnya malah memilih untuk bersekolah di sekolah favorit yang lokasinya lebih jauh namun memiliki fasilitas yang lebih baik. ${ }^{3}$

Persoalan kualitas tenaga pendidik dan kependidikan juga masih banyak dijumpai di beberapa daerah. Sehingga permasalahan ini menyebabkan terjadinya kesejangan. Menurut data rasio guru dan murid SMA tahun 2020 di Propinsi Sumatera Selatan yang

${ }^{2}$ Mona Novita, 2017. "Sarana Prasarana yang Baik menjadi bagian Ujung Tombak Keberhasilan Lembaga Pendidikan, Sekolah Tinggi Agama Islam.” Nur El-Islam 4(2):97-129.

${ }^{3}$ Mona Novita, “Sarana Prasarana...”, 100. 
diakses dari laman npd.kemdikbud.go.id menunjukkan bahwa di Kabupaten Musi Banyuasin (ibu kota Kabupaten adalah Sekayu), Guru PNS-siswa SD=1:38, Guru PNS-Siswa SMP=1:57, Guru PNSsiswa SMA=1:142, Guru PNS-siswa $S M K=1: 78$, Guru-siswa SD=1:18, Guru-siswa $\mathrm{SMP}=1: 17$, Guru-siswa $\mathrm{SMA}=1: 43$ dan guru-siswa $\mathrm{SMK}=1: 23$. Rombel siswa $\mathrm{SD}=23$, rombel siswa $\mathrm{SMP}=32$, rombel siswa $\mathrm{SMA}=72$ dan rombel siswa $\mathrm{SMK}=37$. Sedangkan Menurut Peraturan Menteri Pendidikan dan Kebudayaan Nomor 23 Tahun 2013, tiap SD saja harus memiliki satu guru untuk setiap 32 murid. Realitasnya, pada tahun 2020 rasio murid-guru SD di Kabupaten Musi Banyuasin bernilai 1:38 (lokadata.id). Menurut Direktur Pembinaan Sekolah Dasar Direktorat Jenderal DikdasmenKemendikbud, Khamim "Berdasarkan Standar Nasional Pendidikan (SNP) per rombongan belajar 28 anak," dikutip dari kumparanMOM, yang diterbitkan pada Selasa (26/2/2019). ini menunjukkan rasio guru siswa belum seimbang. ${ }^{4}$

UNESCO dalam Global Education Monitoring (GEM) Report 2016, menerangkan Indonesia peringkat ke 10 dari 14 negara berkembang. Kualitas guru Indonesia berada pada posisi ke-14 dari 14 negara berkembang, dalam Yunus yang dikutip oleh Sri Utami. ${ }^{5}$ Anggaran pendidikan besar namun kenyataannya kualitas pendidikan Indonesia masih berada jauh dari kata memadai. ${ }^{6}$ Masyarakat akan berlomba-lomba masuk ke sekolah favorit yang dianggap memiliki sarana dan prasarana yang lengkap untuk menunjang proses belajar mengajar serta biasanya sekolah pavorit memiliki tenaga pengajar pilihan yang kompeten dan profesional serta prioritas utama dalam pemberian akses untuk mengikuti berbagai perlombaan secara tingkat regional, nasional maupun internasional.

4 https://kumparan.com/kumparanmom/kapasitas-siswa-dalam-satukelas-di-sekolah-dasar-berapa-yang-ideal-155134477543562308o/full.

5 Sri Utami, "Meningkatkan Mutu Pendidikan Indonesia Melalui Peningkatan.” Prosiding Seminar Nasional Pendidikan FKIP 2(1):518-27. 2019.

${ }^{6}$ Mira Marisa dan Akmal Hawi. "Konteks Manajemen Berbasis Sekolah." 10(1):125-38. 2021. 
Dampak bagi sekolah, ada sekolah yang memiliki banyak siswa disisi lain ada sekolah yang kekurangan siswa. Ketidakmerataan ini akan menimbulkan dampak yang tidak baik pada dunia pendidikan nasional, menurut Bintoro dalam Saharuddin. ${ }^{7}$ Karena pentingnya pemerataan akses dan mutu pendidikan, maka Pemerintah menjalankan kebijakan zonasi pendidikan. Implementasi kebijakan zonasi pendidikan merupakan strategi serta upaya Pemerintah melakukan pemerataan akses dan mutu pendidikan. Sistem zonasi dalam pendidikan merupakan landasan pokok penataan reformasi sekolah secara keseluruhan mulai dari Taman Kanak-kanak (TK) hingga Sekolah Menengah Atas (SMA).

Tingginya minat untuk mendaftar kesekolah pavorit dapat dilihat dari banyaknya jumlah pendaftar di Kabupaten Musi Banyuasin bersaing ketat untuk bisa masuk ke SMA Negeri pavorit di Sekayu. SMA tersebut antara lain adalah SMA Negeri 2 Sekayu dan SMA Negeri 1 Sekayu. Hal ini dikarenakan PPDB sudah mampu diakses secara online, dikelola oleh tim IT Profesional dan calon wali murid berkeyakinan bahwa SMA pavorit merupakan sekolah yang berkualitas. SMA pavorit dari tahun ketahun selalu menjadi incaran calon peserta didik baik calon peserta didik dari sekitar wilayah SMA tersebut maupun dari luar wilayah sekolah tersebut. SMA pavorit mempunyai banyak kelebihan, selain sarana prasarananya memadai, letak yang strategis, mudah dijangkau oleh transportasi umum.

Sistem zonasi merupakan sebuah sistem pengaturan proses penerimaan siswa baru sesuai dengan wilayah tempat tinggal. Sistem tersebut diatur dalam Permendikbud Nomor 14 Tahun 2018 dan ditujukan agar tak ada sekolah-sekolah yang dianggap sekolah favorit dan non-favorit. Akan tetapi, pelaksanaan dari sistem ini masih menuai pro dan kontra, sehingga peneliti menilai penting

7 Saharuddin, Erni, dan Muhammad Salisul Hakim. "Implementasi Kebijakan Sistem Zonasi dalam Penerimaan Peserta Didik Baru pada Tingkat SMA di Daerah Istimewa Yogyakarta.” Jurnal Ilmiah Ilmu Administrasi Negara 7(3): 424-38. 2020. 
untuk melakukan penelitian terkait implementasi kebijakan zonasi pada PPDB tingkat SMA di Kabupaten Musi Banyuasin.

\section{Pembahasan}

\section{Perencanaan}

Hal utama dalam PPDB yaitu perencanaan pembentukan panitia PPDB yang dibentuk oleh kepala sekolah selaku penanggung jawab PPDB. Dalam perencanaan PPDB, kepala sekolah menyiapakan segala sesuatu yang sebelumnya dimusyawarahkan terlebih dahulu bersama panitia PPDB. Pada rapat pertama yaitu rapat secara umum yang diikuti oleh semua pendidik dan tenaga pendidik guna mensosialisasikan prosedur PPDB, agar semua pendidik dan tenaga pendidik ikut andil dalam memberikan informasi PPDB kepada masyarakat. Banyak hal yang dipersiapkan dalam PPDB, mulai dari petunjuk teknis, daya tampung, tempat, administrasi, penetapan anggaran, informasi pengumuman PPDB seperti pembuatan banner, brosur, dll.

Perencanaan yang dilakukan ketiga SMA Negeri tersebut selaras dengan pendapat Anang Firmansyah dan Budi W. Mahardika yang mengatakan jika perencanaan tidak hanya menetapkan hal seperti tindakan apa yang harus dikerjakan, apakah sebabnya tindakan itu harus dikerjakan, dimana tindakan itu harus dikerjakan, kapankah tindakan itu dilaksanakan, siapakah yang akan mengerjakan tindakan itu dan, bagaimanakah caranya melaksanakan tindakan itu, tetapi dalam perencanaan penetapan biaya (budget) sudah termasuk didalamnya. ${ }^{8}$ Penyebaran informasi tentang penerimaan peserta didik baru di sekolah/madrasah dengan menggunakan berbagai macam media, meliputi brosur, surat edaran, papan pengumuman, banner, web.

\section{Pengorganisasian}

Menurut Firmansyah dan Mahardika, pengorganisasian adalah keseluruhan kegiatan manajemen dalam mengelompokkan orang-

${ }^{8}$ Anang Firmansyah dan Budi W. Mahardika, Pengantar Manajemen (Yogyakarta: Deepublish, 2018). 11. 
orang serta penetapan tugas, fungsi, wewenang, serta tanggung jawab masing-masing dengan tujuan terciptanya aktivitas-aktivitas yang berdaya guna dan berhasil guna dalam mencapai tujuan yang telah ditentukan. Kepala sekolah membentuk panitia PPDB serta menetapkan tugas-tugsanya setelah menghadiri rapat dinas, dan dikarenakan pendaftaran PPDB dilakukan secara online maka pembentukan panitia PPDB kepala sekolah mengutamakan pendidik dan tenaga pendidikan yang menguasai ICT (Information and Communication Technology) agar perencanaan dapat dilaksanakan secara efektif dan efisien dan sekolah dapat memberikan pelayanan yang baik kepada masyarakat.

Pengorganisasian atau penetapan tugas panitia PPDB:

1. Penanggung jawab: bertanggung jawab secara keseluruhan terhadap pelaksanaan penerimaan peserta didik baru,

2. Ketua Pelaksana: mengkoordinir semua kegiatan PPDB, memonitor pelaksanaan kegiatan PPDB, membuat dan melaksanakan aturan teknis kegiatan PPDB, dan bertanggungjawab kepada penanggungjawab kegiatan PPDB,

3. Sekretaris: menyiapkan semua administrasi kegiatan PPDB, menyusun jurnal sementara PPDB, membuat pengumuman resmi PPDB dan membantu ketua menyusun laporan Pelaksanaan PPDB,

4. Bendahara: mengelola keuangan selama pelaksanaan PPDB, menyusun SPJ pelaksanaan PPDB,

5. Seksi-seksi:

a. Seksi kesekretariatan: menginput data pendaftar pada situs PPDB,

b. Seksi sosialisasi/publikasi: membuat brosur untuk sosialisasi pendaftaran, membuat pengumuman syarat-syarat pendaftaran, mendokumentasikan pelaksanaan PPDB,

c. Seksi pendaftaran: mengecek kelengkapan berkas pendaftar, menuliskan biodata pendaftar ke dalam buku induk,

d. Seksi seleksi: memilah berkas pendaftar yang diterima dan tidak diterima, melayani pencabutan berkas bagi pendaftar 
yang tidak diterima, mengkoordinir tes seleksi kelas unggulan bagi peserta didik baru yang diterima,

e. Seksi monitoring dan evaluasi: memantau dan mengevaluasi pelaksanaan PPDB,

f. Seksi keamanan: menjaga keamanan secara keseluruhan selama pelaksanaan PPDB. ${ }^{9}$

\section{Pelaksanaan}

Pelaksanaan adalah rangkaian kegiatan yang dilakukan setelah dirumuskan perencanaan dan pengorganisasian. Pelaksanaan dilakukan ketika perencanaan telah dirumuskan, termasuk anggaran biaya yang diperlukan atau yang diharapkan, struktur organisasi, dan tim kerja serta kebutuhan untuk menunjang pelaksanaan sudah siap.

Pelaksanaan PPDB mengusung 5 prinsip, yaitu:

1. Non diskriminatif artinya semua warga negara yang berusia sekolah berhak mengikuti program pendidikan di Indonesia tanpa membedakan suku, daerah, agama, dan golongan. Prinsip ini dikecualikan bagi sekolah yang secara khusus melayani peserta didiki dari kelompok gender atau agama tertentu,

2. Objektif artinya pelaksanaan PPDB harus dilaksanakan sesuai ketentuan dari pemerintah,

3. Transparan, pelaksanaan PPDB bersifat terbuka, dapat diketahui oleh masyarakat, termasuk orang tua/wali dan calon peserta didik,

4. Akuntabel berarti PPDB dapat dipertanggung jawabkan kepada pemerintah maupun masyarakat baik prosedur maupun hasilnya dalam Ali Muhammad ( Rohmah, 2020).

5. Berkeadilan artinya pelaksanaan PPDB harus mengutamakan keadilan. ${ }^{10}$

9 Rohmah, Sheila, Wahyudi Wahyudi, dan Fanzal Pamungkas. "Pengelolaan Penerimaan Peserta Didik Baru (PPDB) Berdasarkan Sistem Zonasi di SMP Negeri 1 Mlonggo Jepara.” Jawda: Journal of Islamic Education Management 1(1):25. doi: 10.21580/jawda.vili.2020.6704. 2020, 29.

${ }^{10}$ Rohmah, dkk., "Pengelolaan Penerimaan...", 29. 
Penerimaan Peserta Didik Baru (PPDB) Tingkat SMA Negeri di Sekayu Tahun Pelajaran 2021/2022 dibuka dengan ketentuanketentuan kuota sebagai berikut:

a. Jalur Afirmasi

\section{SMAN 2 Unggul Sekayu (Sistem PPDB SMA Negeri Berasrama di Sumatera Selatan)}
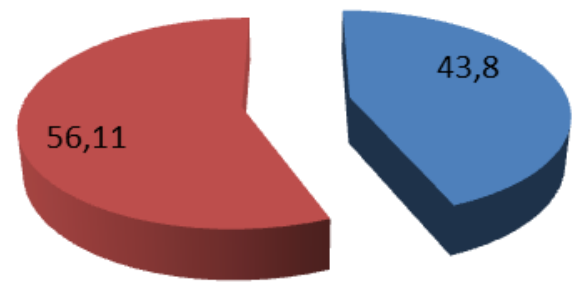

- Jalur Seleksi PPMA

- Jalur Selekasi TPA

Gambar 1. Diagram PPDB SMA Negeri 2 Unggul Sekayu

Afirmasi

1) Diperuntukkan bagi peserta didik dengan kondisi ekonomi tidak mampu atau peserta didik dengan disabilitas

2) Memiliki KIP / kartu PKH

Mutasi Kerja Orang Tua

3) Diperuntukkan bagi peserta didik dengan kondisi mengikuti perpindahan tugas orang tua.

4) Melampirkan Surat Tugas Perpindahan Kerja Orang Tua TMT 1 Juli 2020 keatas

\section{Prestasi Non Akademik}

1) KSN, $\mathrm{O}_{2} \mathrm{SN}, \mathrm{FLS}_{2} \mathrm{~N}$, Popda/ Porprov/ Pornas, olahraga perorangan, Lomba Tingkat (LT) Pramuka, Jambore Nasional Pramuka, MTQ dan Lomba Cerdas Cermat 
(LCC) minimal sebagai Juara 1 atau 2 atau 3, Tingkat Kabupaten/Kota.

2) Hafal Al Qur'an minimal 3 juz yang dibuktikan dengan piagam

\section{Prestasi Akademik}

1) Selalu mendapat juara kelas (Juara I atau Juara II atau Juara III) selama semester 1 s.d. semester 5 yang dibuktikan dengan piagam

b. Jalur Tes

1) Nilai rata-rata Raport SMP/MTs sederajat Semester 1 s.d. 5 minimal 8 o.

2) Nilai rata-rata raport untuk mata pelajaran Matematika, Bahasa Indonesia, Bahasa Inggris, IPA dan IPS dari Semester 1 s.d 5 minimal 8o.

Tabel 1. Jadwal Pendaftaran (online) PPDB SMA Negeri 2

\begin{tabular}{|l|l|l|l|}
\hline No. & \multicolumn{1}{|c|}{ Kegiatan } & \multicolumn{1}{c|}{ Waktu } & \multicolumn{1}{c|}{ Keterangan } \\
\hline $\mathbf{1}$ & $\begin{array}{l}\text { Pendaftaran Jalur } \\
\text { PPMA }\end{array}$ & 22-24 Maret 2021 & Pendaftar 97 siswa \\
\hline $\mathbf{2}$ & Pengumuman & 29 Maret 2021 & lulus 79 siswa \\
\hline 3 & $\begin{array}{l}\text { Pendaftaran Jalur } \\
\text { TPA }\end{array}$ & 12-16 April 2021 & Pendaftar 181 siswa \\
\hline 4 & Pengumuman & 26 April 2021 & lulus 101 siswa \\
\hline \multicolumn{2}{|c|}{ Jumlah total } & diterima 180 siswa \\
\hline
\end{tabular}




\section{PPDB Sistem Zonasi SMAN 1 Rujukan Sekayu}
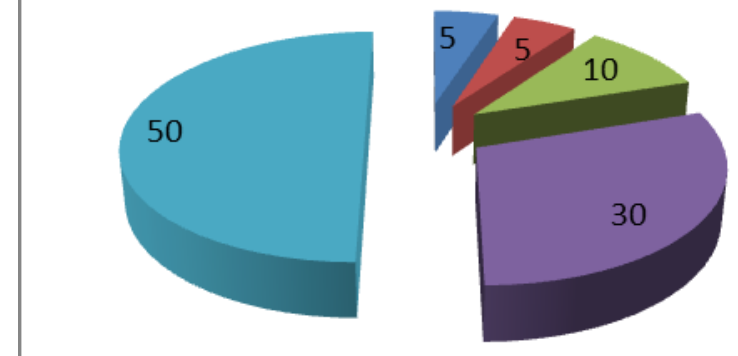

- Jalur Afirmasi

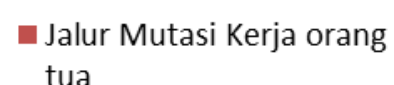
tua

- Jalur PMPA

- Jalur Zonasi

- Jalur TPA

Gambar 2. Jalur PPDB di SMAN 1 Rujukan Sekayu

Ketentuan sistem zonasi tertera dalam Permendikbud No. 44 tahun 2019, yang dijelakan bahwa dalam pendaftaran PPDB dilaksanakan melalui jalur berikut:

1. Jalur zonasi paling sedikit 50\% daya tampung sekolah. Domisili tersebut berdasarkan alamat pada kartu keluarga atau bisa diganti dengan surat keterangan domisili dari RT/RW yang dilegalisir oleh lurah/kepala desa atau pejabat setempat lain yang berwenang menerangkan bahwa peserta didik yang bersangkutan telah berdomisili paling singkat 1 tahun sejak diterbitkannya surat keterangan domisili.

2. Jalur afirmasi paling sedikit $15 \%$ dari daya tampung sekolah. Jalur afirmasi diperuntukkan bagi peserta didik domisili dalam dan luar wilayah zonasi sekolah yang berasal dari keluarga ekonomi tidak mampu yang dibuktikan dengan keikutsertaan peserta didik dalam program penanganan keluarga tidak mampu dari pemerintah pusat atau pemerintah daerah. 
3. Jalur perpindahan tugas orang tua/wali paling banyak $5 \%$ dari daya tampung sekolah yang dibuktikan dengan surat penugasan dari instansi, lembaga, kantor, atau perusahaan yang memperkerjakan.

4. Jika dari keempat jalur diatas masih terdapat sisa kuota maka pemerintah daerah dapat membuka jalur prestasi yang ditentukan berdasarkan:

1) Nilai ujian sekolah atau UN.

2) Hasil perlombaan atau penghargaan di bidang akademik maupun non akademik pada tingkat internasional, nasional, provinsi, atau tingkat kabupaten/kota yang diterbitkan paling singkat enam bulan dan paling lama tiga tahun sejak tanggal pendaftaran PPDB.

Ketentuan mengenai jalur pendaftaran PPDB diatas dikecualikan bagi sekolah berikut:

1) Sekolah yang diselenggarakan oleh masyarakat,

2) SMK yang diselenggarakan oleh pemerintah daerah,

3) Sekolah kerja sama,

4) Sekolah Indonesia di luar negeri,

5) Sekolah yang menyelenggarakan pendidikan khusus,

6) Sekolah yang menyelenggarakan pendidikan layanan khusus,

7) Sekolah berasrama,

8) Sekolah di daerah tertinggal, terdepan, dan terluar (3T),

9) Sekolah di daerah yang jumlah penduduk usia sekolah tidak dapat memenuhi ketentuan jumlah peserta didik dalam satu rombongan belajar.

Pelaksanaan pendaftaran peserta didik baru dilaksanakan secara online melalui website www.sman1-sekayu.sch.id Adanya pandemi covid-19 mengharuskan pendaftaran dilakukan secara online mandiri. Namun pada kenyataanya masih banyak masyarakat yang kurang paham akan tata cara pendaftaran dan masih ada beberapa proses yang mengharuskan siswa datang ke sekolah sesuai protokol covid-19.

Tata cara pendaftaran calon peserta didik baru yaitu: 
1. Calon peserta didik melakukan pendaftaran secara online pada web https://www.smanı-sekayu.sch.id/index.php?id.

2. Mengunggah (upload) kelengkapan pendaftaran terdiri dari;

a. Surat kelulusan dari sekolah/Madrasah/Kejar paket,

b. KK dan KTP orang tua/wali.

c. Salah satu bukti prestasi jenjang tertinggi bidang akademik/olahraga/kesenian/keterampilan atau dalam bidang lainnya dalam kurun waktu tahun 2019 s/d 2021.

d. Surat keterangan miskin dari dinas/instansi yang berwenang,

e. KIP bagi yang memiliki.

f. Surat perpindahan tugas orang tua calon peserta didik dari dinas/instansi/lembaga tempat orang tua bekerja (apabila ada).

3. Mencetak tanda bukti pendaftaran.

4. Menyerahkan tanda bukti pendaftaran ke sekolah yang dituju untuk diverifikasi petugas PPDB.

5. Melihat jurnal harian dan pengumuman hasil PPDB online setiap hari yang dapat diakses melalui internet maupun handphone. Atau dapat datang melihat pengumuman ke sekolah yang bersangkutan sesuai dengan protokol penanggulangan covid-19.

6. Proses pencabutan pendaftaran bagi siswa yang masih diterima pada jurnal seleksi dan ingin pindah sekolah akan diproses oleh panitia PPDB kabupaten paling lambat sehari sebelum tanggal penutupan 24 April 2021 pukul 13.00 maksimal 2 kali.

Alur pendaftaran calon peserta didik baru yaitu adanya kebijakan sistem zonasi proses seleksi peserta didik baru dilakukan oleh sistem pendaftaran online secara otomatis berdasarkan ketentuan kebijakan dari pemerintah. Pihak sekolah tidak ikut andil dalam tahapan ini. Langkah pertama pendaftaran PPDB yaitu siswa mengajukan akun, kemudian memilih jalur PPDB dan memilih 2 pilihan sekolah. Jika jalur pertama yang dipilih tidak sesuai dengan sekolah pilihan 1, maka otomatis pindah ke sekolah 
pilihan. Jika sekolah pilihan 2 tidak diterima juga, maka lanjut seleksi menggunakan jalur pilihan kedua.

Tabel. Jadwal Pelaksanaan PPDB SMA Negeri 1

\begin{tabular}{|l|l|l|l|}
\hline No. & \multicolumn{1}{|c|}{ Kegiatan } & \multicolumn{1}{c|}{ Waktu } & Keterangan \\
\hline 1 & $\begin{array}{l}\text { Pendaftaran jalur } \\
\text { prestasi , afirmasi, dan } \\
\text { mutasi orang tua. }\end{array}$ & 24-25 Mei 2021 & \\
\hline 2 & Pengumuman & 02 Juni 2021 & \\
\hline 3 & Pendaftaran jalur zonasi & 7-12 Juni 2021 & \\
\hline 4 & Pengumuman & 14 Juni 2021 & \\
\hline 5 & Tes Potensi Akademik & 23-25 Juni 2021 & \\
\hline 6 & Pengumuman & 29 Juni 2021 & 400 siswa \\
\hline 7 & jumlah pendaftar & & 360 siswa \\
\hline 8 & jumlah lulus/diterima & & \\
\hline
\end{tabular}

\section{PPDB Sistem Zonasi SMAN 4 Reguler Sekayu}

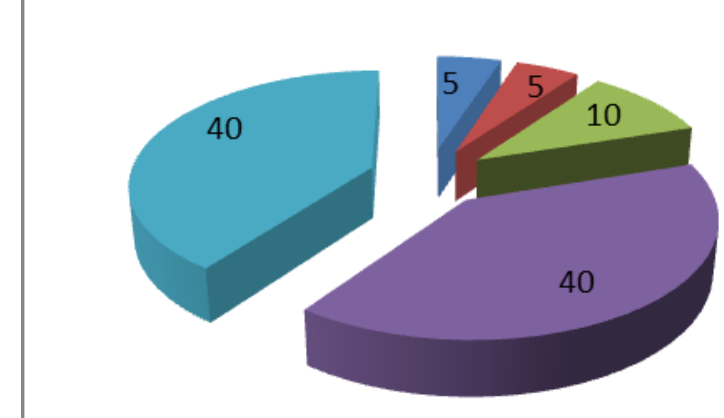

n Jalur Afirmasi

- Jalur Mutasi Kerja orang tua

- Jalur PMPA

- Jalur Zonasi

- Jalur TPA

Gambar 3. diagram menunjukkan PPDB di SMAN 4 Reguler Sekayu 
Menurut Anderson ada empat komponen dalam implementasi kebijakan pendidikan, (1) siapa yang mengimplementasikan kebijakan pendidikan itu, (2) proses administrasi, (3) kepatuhan yang diharapkan, (4) dampak pelaksanaan kebijakan pendidikan itu. ${ }^{1}$ Menurut Ripley and Franklin ada dua hal menjadi fokus implementasi kebijakan pendidikan, (1) Kepatuhan (compliance) para pelaksana terhadap prosedur dan standar operasional yang sudah disepakati; (2) Hal apa saja yang terjadi pada proses implementasi, apa hambatan dan apakah sudah berhasil atau belum. $^{12}$ Kebijakan pemerintah Indonesia mengenai PPDB dilaksanakan pendaftaran secara online dan offline serta memberikan pelayanan yang prima kepada masyarakat. UU Nomor 20 Tahun 2003 tentang Sisdiknas dalam Pasal 5 ayat 1 menyebutkan bahwa setiap warga negara mempunyai hak yang sama untuk memperoleh pendidikan yang bermutu.

Nadiem menyatakan, tidak semua daerah siap menjalankan kebijakan zonasi. Karena itu Kemendikbud mengeluarkan kebijakan kompromi dari zonasi dengan menambah kuota jalur prestasi menjadi zo persen (sebelumnya 15 persen), dan mengurangi kuota jalur zonasi menjadi minimal 70 persen (sebelumnya minimal 80 persen). Kuota zonasi sebesar 70 persen harus mengikuti kriteria, yaitu minimum jalur zonasi 50 persen, jalur afirmasi (pemegang Kartu Indonesia Pintar) 15 persen, dan jalur perpindahan 5 persen. Kemudian sisa kuota 30 persen untuk jalur prestasi. ${ }^{13}$

Berdasarkan teori kebijakan di atas, maka dapat dijabarkan bahwa (1) Kebijakan PPDB online sudah diimplementasikan untuk tingkat SMA. (2) Proses administrasi sudah berjalan sesuai prosedur kebijakan dan aturan yang berlaku. (3) Kepatuhan yang diharapkan

${ }^{11}$ Arwildayanto, Arifin Suking, dan M. P. Sumar, Tune Sumar. Analisis Kebijakan Pendidikan Kajian Teoritis, Eksploratif dan Aplikatif. Bandung: Cendikia Press, 2018, 80.

${ }^{12}$ Arwildayanto, dkk., “Analisis Kebijakan...” 2018, 80.

${ }^{13}$ https://tirto.id/enAD Artikel "Aturan Baru Zonasi PPDB 2020 yang Ditetapkan Nadiem Makarim". Diakses pada tanggal 29 Juni 2021. 
sudah tercapai karena implementasi PPDB di Sekayu sudah dilaksanakan dengan baik dan berasaskan keadilan. (4) Dampak pelaksanaan kebijakan PPDB onlie mengajak masyarakat mau tak mau harus belajar teknologi dengan mengakses web sekolah, Memudahkan siswa yang bertempat tinggal jauh dari sekolah untuk melakukan pendaftaran, mengurangi resiko penyebaran Covid-19,

Kebijakan sekolah zonasi memang sudah baik adanya namun ada sekolah yang dikecualikan salah satunya adalah sekolah berasrama dan unggul seperti SMA Negeri 2 unggul Sekayu, yang melaksanakan PPDB non Zonasi. ${ }^{14}$ Selain itu ada pula kebijakan PPDB zonasi untuk sekolah rujukan seperti SMA Negeri 1 Rujukan Sekayu yang merupakan salah satu sekolah pavorit di Sekayu berhak menjaring siswa lebih banyak melalui jalur TPA yaitu sebanyak $50 \%$ sedangkan jalur zonasinya hanya $30 \%$. Adapun sekolah Reguler seperti SMA Negeri 4 Sekayu melaksanakan PPDB dengan sistem yang sama dengan SMA Rujukan namun perbedaannya terdapat pada persentasi jumlah siswa yang masuk lewat jalur zonasi lebih besar yaitu 40\% sedangkan jalur tes sebesar $40 \% .^{15}$

Dinilai sudah baik dan berasaskan keadilan karena ada sebagian siswa yang memiliki potensi diri walaupun wilayah tempat tinggalnya jauh dari dari sekolah ia berhak untuk mendapatkan pendidikan yang lebih bermutu. Disisi lain ada sekolah yang sudah memenuhi katergori "unggul" atau "rujukan" dan memang sekolahsekolah seperti itu berhak untuk berkembang sesuai kriteria yang telah dicapainya. Kebijakan pendidikan ini harusnya dapat menjadi motivasi bagi siswa-siswa untuk belajar lebih giat, bagi orang tua untuk lebih memberikan waktu khusus mendampingi anak belajar

14 Pemerintah Propinsi Sumatera Selatan. "Petunjuk Teknis (Juknis) Pelaksanaan Penerimaan Peserta Didik Baru (PPDB) SMA Negeri Berasrama di Sumatera Selatan Tahun Pelajaran 2021/2022." Palembang: Dinas Pendidikan, 2021.

${ }^{15}$ Pemerintah Propinsi Sumatera Selatan "Petunjuk Teknis Penerimaan Peserta Didik Baru (PPDB) SMA Negeri Rujukan Kabupaten/Kota dan SMA Negeri Reguler Provinsi Sumatera Selatan Tahun Pelajaran 2021/2022” Palembang: Dinas Pendidikan, 2021. 
agar anak semangat, juga menanamkan nilai-nilai sportifitas sejak dini bahwa siswa yang lebih rajin belajar dan lebih giat berusaha untuk meraih tujuan masuk ke sekolah-sekolah paforit memang berhak atas usahanya sendiri. Termasuk bagi siswa yang kurang mampu secara finansial tetap berhak masuk ke sekolah pavorit jika memenuhi kriteria sesuai ketentuan yang berlaku. Motivasi bagi sekolah lain, lebih termotivasi untuk meningkatkan mutu lembaga pendidikan agar lebih baik.

\section{Pengawasan}

Kegiatan pengawasan (suvervisi) akademik dan pengawasan (supervisi) supervisi manajerial dilakukan oleh pengawas sekolah untuk meningkatkan mutu pendidikan di sekolah. ${ }^{16}$ Pengawasan (supervisi) sekolah manajerial adalah fungsi supervisi yang berkenaan dengan aspek pengelolaan sekolah yang terkait langsung dengan peningkatan efisiensi dan efektivitas sekolah yang mencakup hal seperti perencanaan, koordinasi, pelaksanaan, penilaian, pengembangan kompetensi SDM kependidikan dan sumberdaya lainnya. Fungsi pengawasan adalah membantu kepala sekolah dan staf sekolah lainnya dalam mengelola administrasi pendidikan seperti administrasi kurikulum, administrasi keuangan, administrasi sarana prasarana, administrasi personal atau ketenagaan, administrasi kesiswaan, adminis hubungan sekolah dan masyarakat, administrasi budaya dan lingkungan sekolah, serta aspek-aspek administrasi lainnya dalam rangka meningkatkan mutu pendidikan.

Kegiatan pengawasan dilakukan oleh kepala sekolah sebagai penanggung jawab PPDB. Kepala sekolah mengadakan rapat evaluasi setiap akhir jam pelayananan PPDB. Rapat ini diadakan selama proses pendaftaran peserta didik baru. Rapat evaluasi dilaksanakan bertujuan untuk mengetahui dan memberikan penilaian terhadap proses pelaksanaan pendaftaran peserta didik

${ }^{16}$ Badani, M. Nur Mustafa, Hasnah Faizah AR. "Peranan Pengawas Sekolah dalam Meningkatkan Mutu Pendidikan SDN di Kecamatan Rumbio Jaya", Jurnal Manajemen Pendidikan Vol. 4 No.1 Maret : pp.19-26 2020, 21. 
baru apakah sudah berjalan sesuai dengan petunjuk teknis (juknis), apakah terdapat kekurangan atau kesalahan. Jika memang ada maka dapat terdeteksi untuk diperbaiki secepatnya. Agar pada proses pendaftaran peserta didik baru di kemudian hari maupun tahun ajaran berikutnya dapat berjalan semakin baik. Kepala sekolah juga mengadakan rapat sebelum pembuatan jurnal atau laporan PPDB. Dalam rapat ini dapat pula meminta pendapat atau masukan untuk evaluasi PPDB selanjutnya, dapat pula mendengarkan tentang kendala-kendala yang dihadapi oleh panitia PPDB.

Modul Khusus Komunitas PNPM Mandiri yang berjudul Transparansi Akuntabilitas pengertian transparansi adalah prinsip yang menjamin akses atau kebebasan bagi setiap orang untuk memperoleh informasi tentang penyelenggaraan suatu lembaga/perorangan, seperti keuangan, program, penerima manfaat, dll. Akuntabilitas adalah prinsip yang menjamin bahwa setiap kegiatan dapat dipertangungjawabkan secara terbuka kepada masyarakat. Diakses pada laman kotaku.pu.go.id. Transparansi adalah memberi informasi kepada masyarakat mengenai kegiatan PPDB online dapat berupa pembukuan, program dan lain-lain. Transparansi dan akuntabilitas mengandung nilai-nilai kejujuran. Karena apabila tidak dijalankan dapat menimbulkan fitnah atau prasangka kurang baik bahkan dapat manimbulkan konflik antara pihak sekolah dan masyarakat. Transparansi akan menumbuhkan kepercayaan penuh. Bukti nyata transparasi PPDB di Sekayu adalah adanya pengumuman kelulusan yang dapat diketahui secara terbuka oleh setiap lapisan masyarakat termasuk oleh orang yang tidak mengikuti PPDB tersebut. Waktu dan tempat penyelenggaraan PPDB online dapat pula diketahui melalui laman website atau pun spanduk pengumuman pelaksanaan PPDB online.

Menurut Boyke Lesmana, Ketua Pelaksana PPBD online SMA Negeri 2 Sekayu dari wawancara kepada beliau melalui aplikasi Whatapp pada tanggal 26 Juni 2021, didapat informasi bahwa proses PPDB online tingkat SMA di Sekayu telah melalui proses pengawasan, yaitu pada saat pelaksanaan dilakukan 
monitoring/pengawasan oleh Dinas Pendidikan Provinsi Sumatera Selatan, tepatnya saat proses pelaksanaan tes tertulis sampai dengan perhitungan akhir yang di tayangkan secara online melalui media sosial "facebook" dan "Instagram". ${ }^{17}$

Setelah selesai pelaksaan PPDB online ada Monitoring dan evaluasi (Monev) dari pengawas pembina serta Lembaga Penjaminan Mutu Pendidikan (LPMP). Unit Pelaksana Teknis Kementerian Pendidikan Dan Kebudayaan yang berada di bawah dan bertanggungjawab kepada Direktur Jenderal Pendidikan Dasar dan Menengah. Proses Monitoring dan Evaluasi atau yang lebih sering kita kenal dengan istilah Monev merupakan salah satu tahapan penting dalam pelaksanaan suatu program kerja. Mengapa dinilai penting? Hal ini dilakukan karena Monev dapat membantu pengguna dalam menilai kesesuaian antara apa yang direncanakan dengan hasil yang diwujudkan.

\section{Simpulan}

Perencanaan kegiatan PPDB dilakukan sesuai juknis dari pemerintah. Hal utama dari perencanaan PPDB yaitu membentuk tim atau panitia PPDB dan menyusun struktur organisasi serta penetapan tugasnya sehingga setiap panitia dapat fokus bekerja sesuai dengan tugas masing-masing. Pendaftaran peserta didik dilakukan secara online, maka dari itu pembentukan panitia PPDB dipilih berdasarkan karyawan atau pegawai yang menguasai ICT (Information and Communication Technology). Pelaksanaan pendaftaran dilakukan secara online mandiri melalui website sekolah masing-masing. Proses pendaftaran dijalankan sesuai dengan protokol Covid-19. Proses seleksi secara otomatis dilakukan oleh sistem dan pengumuman peserta didik yang lulus seleksi diumumkan di website pendaftaran maupun disampaikan langsung kepada peserta melalui pesan singkat. Pengumuman dengan memasang spanduk di pagar sekolah mengenai waktu pelaksanaan PPBD dan kelulusan peserta didik yang lulus seleksi di laman web

${ }^{17}$ Boyke Lesmana, Ketua Pelaksana PPBD online SMA Negeri 2 Sekayu, Wawancara, Sekayu, 26 Juni 2021 
sekolah, bertujuan agar semua masyarakat dapat melihat informasi kapanpun. Tahap rapat penentuan peserta didik yang diterima dalam prosedur PPDB tidak berlaku pada PPDB berdasarkan sistem zonasi. Pengawasan kegiatan PPDB dilakukan kepala sekolah selaku penanggung jawab PPDB, diantaranya dengan mengadakan rapat evaluasi setiap akhir jam pelayananan PPDB yang diadakan selama proses pendaftaran peserta didik baru, rapat sebelum pembuatan jurnal atau laporan PPDB.

\section{Referensi}

Arwildayanto, Arifin Suking, dan M. P. Sumar, Tune Sumar. Analisis Kebijakan Pendidikan Kajian Teoritis, Eksploratif dan Aplikatif. Bandung: Cendikia Press, 2018.

Badani, M. Nur Mustafa, Hasnah Faizah AR. "Peranan Pengawas Sekolah dalam Meningkatkan Mutu Pendidikan SDN di Kecamatan Rumbio Jaya”, Jurnal Manajemen Pendidikan Vol. 4 No.1 Maret : pp.19-26 2020.

Cropper, Rebecca J. "A Management Approach to Country Extension Progams." Journal of Extension 36, no. 6. 1998.

Firmansyah, Anang dan Budi W. Mahardika, Pengantar Manajemen. Yogyakarta: Deepublish, 2018.

Hambali, Muh. dan Mualimin, Manajemen Pendidikan Islam Kontemporer, Yogyakarta: IRCISOD Indonesia. 2020.

http. Litbang.kemdikbud.go.id

http://kotaku.pu.go.id:8o81/pustaka/files/modul_pelatihano8/A/2/e/

(3)/Modul-Transparansi-Akuntabilitas.pdf

https://kumparan.com/kumparanmom/kapasitas-siswa-dalam-satukelas-di-sekolah-dasar-berapa-yang-ideal$1551344775435623080 /$ full

https://lokadata.id/artikel/rasio-murid-guru-cukup-sebaran-masihkurang 
https://lpmpbali.kemdikbud.go.id/2020/o1/29/kebijakan-mendikbudaturan-baru-jalur-zonasi-ppdb-2020/

https://peraturan.bpk.go.id/Home/Details/146661/pergub-provsumatera-selatan-no-8-tahun-2020

https://repository.unsri.ac.id/37329/45/RAMA_63201_o7011381520119 _0017116502_0005065709_01_FRONT_REF.pdf

https://tirto.id/enAD "Aturan Baru Zonasi PPDB 2020 yang Ditetapkan Nadiem Makarim". Diakses pada tanggal 29 Juni 2021.

https://www.sman1-sekayu.sch.id/index.php?id=profil\&kode=109

https://www.smanzsekayu.sch.id/ppdb-sman-2-sekayu-jalurpmpa.html

Kristiawan, Muhammad dan Jimmi Yuliandri, Manajemen Pendidikan Yogyakarta: Deepublish. 2017.

Marisa, Mira, dan Akmal Hawi. "Konteks Manajemen Berbasis Sekolah.” 10(1):125-38. 2021.

Miles, Matthew B, dan A Michael Huberman. An Expanded Sourcebook Qualitative Data Analysis. 2 ed. London: Sage Publications, 1994.

Mu'ammar, M Arfan. Nalar Kritis Pendidikan. Yogyakarta: Ircisos, 2019 .

Novita, Mona. "Sarana Prasarana yang Baik menjadi bagian Ujung Tombak Keberhasilan Lembaga Pendidikan, Sekolah Tinggi Agama Islam.” Nur El-Islam 4(2):97-129. 2017.

Pemerintah Propinsi Sumatera Selatan "Petunjuk Teknis Penerimaan Peserta Didik Baru (PPDB) SMA Negeri Rujukan Kabupaten/Kota dan SMA Negeri Reguler Provinsi Sumatera Selatan Tahun Pelajaran 2021/2022" Palembang:Dinas Pendidikan, 2021. 
Pemerintah Propinsi Sumatera Selatan. "Petunjuk Teknis (Juknis) Pelaksanaan Penerimaan Peserta Didik Baru (PPDB) SMA Negeri Berasrama di Sumatera Selatan.” Palembang: Dinas Pendidikan, 2021.

Peraturan Gubernur Nomor 8, BD.2020/No. 9 tentang Penerimaan Peserta Didik Baru pada Sekolah Menengah Atas dan Sekolah Menengah Kejuruan di Provinsi Sumatera Selatan.

Peraturan Menteri Pendidikan dan Kebudayaan Nomor 44 Tahun 2019 tentang Penerimaan Peserta Didik Baru pada TK, SD, SMP, SMA dan SMK atau Bentuk Lain yang Sederajat.

Purwanti, Dian, Ira Irawati, Jossi Adiwisastra, dan Herijanto Bekti. "Implementasi Kebijakan Penerimaan Peserta Didik Baru Berdasarkan Sistem Zonasi Di Kota di Kota Bandung.” Jurnal Governansi 5, no. 1. 2019.

Rohmah, S., Wahyudi, W., \& Pamungkas, F. Pengelolaan Penerimaan Peserta Didik Baru (PPDB) Berdasarkan Sistem Zonasi di SMP Negeri 1 Mlonggo Jepara. Jawda: Journal of Islamic Education Management, 1(1), 25. https://doi.org/10.21580/jawda.v1i1.2020.6704. 2020.

Saharuddin, Erni, dan Muhammad Salisul Hakim. "Implementasi Kebijakan Sistem Zonasi dalam Penerimaan Peserta Didik Baru pada Tingkat SMA di Daerah Istimewa Yogyakarta." Jurnal Ilmiah Ilmu Administrasi Negara 7(3):424-38. 2020.

Saifuddin. Pengelolaan Pembelajaran Teoritis dan Praktis. Yogyakarta: Deepublish. 2014.

Syafril, dan Zelhendri Zen. Dasar-Dasar Ilmu Pendidikan. Depok: Kencana. 2017.

Undang-Undang No. 20 Tahun 2003. Sistem Pendidikan Nasional.

Utami, Sri. 2019. "Meningkatkan Mutu Pendidikan Indonesia Melalui Peningkatan." Prosiding Seminar Nasional Pendidikan FKIP 2(1):518-27. 
JIEMAN: Journal of Islamic Educational Management

Zamzam, Firdaus Fakhry. Aplikasi Metodologi Penelitian. Aplikasi Metodologi Penelitian. Yogyakarta: Deepublish. 2018. 